The results of the MBI further confirmed that $85 \%$ of physicians were facing moderate-high level burnout which declined after the roster change to $33 \%$.

Burnout is a growing problem among physicians and can possibly lead to devastating consequences therefore requiring immediate interventions $1,2,3,4,5,6,7,8$. The results revealed that an uneven layout of shifts and breaks within the cycle contributed to high burnout levels which hugely declined after taking into account physicians preferences.

\section{HIGH BLOOD PRESSURE AND OBESITY PREVALENCE IN ADOLESCENTS IN BUDAPEST: RESULTS OF A SCREENING PROGRAM}

${ }^{1,2}$ L Szabó*, ${ }^{1} \mathrm{~J}$ Kormos-Tasi, ${ }^{1} \mathrm{E}$ Gácsi, ${ }^{2} \mathrm{~N}$ Scheuring. ${ }^{1}$ Department of Family Care Methodology, Institute of Health Science, Semmelweis University Budapest, Hungary; ${ }^{2}$ Heim Pál Children Hospital, Budapest, Hungary

10.1136/archdischild-2021-europaediatrics.49

Obesity is a growing problem worldwide and is likely a major cause of the increased prevalence of high blood pressure in children. The aim of the screening program was to investigate the association of blood pressure levels and obesity, hypercholesterinaemia and increased body fluid in adolescents.

2202 children participated in the screening program. Blood pressure, heart rate, body composition, cholesterol and blood glucose level, bodyweight, height and BMI were assessed.

The participants' range of age was between 14-18 years. The average systolic blood pressure (SBP) was $126.34+12.55$ mmHg. Boys had higher SBP than girls $(131.87+13.59$ $\mathrm{mmHg}$ versus $117.49+5.69 \mathrm{mmHg}, \mathrm{p}<0,001)$. The average diastolic blood pressure (DBP) was $71.86+8.74 \mathrm{mmHg}$. DBP was also higher in boys than girls $(72.61+9.17 \mathrm{mmHg}$ versus $66.69+5.04 \mathrm{mmHg}, \mathrm{p}<0,001$ ). High SBP (>percentile 95\%) was detected in 307/1326 cases in girls, and in 403/876 cases in boys. High DBP occurred in 85 girls and in 90 boys. Overweight and obese were $18.994 \%$ of the girls and $15.26 \%$ of the boys. The percentage of high blood pressure was more frequent among boys and girls who were in the overweight group $(58,6 \%$ and $18,6 \%)$. The pathologically high level of body fat percentage appeared to be $12.98 \%$ among girls and $5.9 \%$ among boys. In elevated BMI groups the frequency of high body fat was 66\% among girls and $81 \%$ among boys. The mean cholesterol level was significantly higher $(\mathrm{p}<0,001)$ in the overweight $(4.05 \mathrm{mmol} / \mathrm{l})$ and obese group $(4.17 \mathrm{mmol} / \mathrm{l})$.

Prevalence rates of hypertension and overweight and obesity are high in school children in Budapest, and increased bodyweight is a significant risk factor for hypertension. The results of the study will help to design preventive programmes.

\section{INCIDENTAL FINDING OF CONGENITAL DIAPHRAGMATIC HERNIA AND TRISOMY 21 IN AN INFANT PRESENTING WITH BRONCHIOLITIS}

Abhidhamma Kaninde*, A Naeem, T Dungarwalla, Thomas Rootsey, R Ramaswamy. Peterborough City Hospital

10.1136/archdischild-2021-europaediatrics.50

Introduction Trisomy 21 is still the most commonly encountered chromosomal abnormality in the world despite advances in prenatal diagnostic measures. As screening tests in the antenatal period have limitations(Kater-Kuipers, Bunnik, de Beaufort, \& Galjaard, 2018), it is not uncommon to make new diagnoses of trisomy 21 postnatally.

Trisomy 21 is associated with multiple anomalies including congenital heart disease (65\%) (Martin, 2018), and gastrointestinal tract anomalies 6\%(Stoll, Dott, Alembik, \& Roth, 2015). Some studies report infant mortality of about $6 \%$ in trisomy 21.(Martin et al., 2018)

Case Summary We report a case of 8-month-old, previously fit and healthy baby presenting to our assessment unit with cough, coryza and increasing breathlessness. On assessment, he was noted to have respiratory distress, oxygen requirement and a respiratory acidosis on blood gas analysis. He was diagnosed with RSV negative Bronchiolitis. He was admitted and commenced on humidified high flow nasal cannula with oxygen requirement up to $40 \%$. Over the next 3 days, he was weaned to nasal canula oxygen and started nasogastric feeds.

After discontinuation of humidified oxygen, he was noted to have facial dysmorphism, specifically slanted palpebral fissures, protruding tongue and single palmar creases. In view of a persistent oxygen requirement and a gurgling sound and crepitations on auscultation disproportionate to his symptoms, a chest $\mathrm{x}$-ray was requested.

It was reported to be suspicious of left diaphragmatic hernia with associated mediastinal displacement to right side.

Further imaging with computed tomography confirmed a left sided Morgagni's diaphragmatic hernia with multiple bowel loops and the left lobe of liver.

The patient was transferred to a tertiary Paediatric unit for surgical correction. He was operated successfully without any complications and discharged home. His genetic testing was later reported as confirmatory of non-dysjunctional trisomy 21.

Discussion Traditionally, trisomy 21 is described as a syndrome with the classic phenotype of slanted palpebral fissure, hypotonia and learning difficulty.

In one study from Saudi Arabia (Al-Salem et al., 2014), out of 53 infants with Morgagni's hernia 15 (28.3\%) had down syndrome.

Benachi et el describe the antenatal detection rate in Europe reaching up to $60 \%$ (Benachi, Cordier, Cannie, \& Jani, 2014) suggesting that up to $40 \%$ diaphragmatic hernias could potentially be missed antenatally.

Conclusion Delayed diagnosis of trisomy 21 although not the norm, is not unusual.

One should be proactive in offering genetic tests in suspected trisomy 21 and once diagnosed should be thoroughly screened to diagnose associated anamolies.

\section{ROHHAD SYNDROME: CLINICAL CASE AND LITERATURE REVIEW}

LA Balykova*, NV Ivyanskaya, ES Samoshkina, SA Ivyansky, AF Kudashova, DS Bogdashova. Medicine Institute, National Research Ogarev Mordovia State University

\subsection{6/archdischild-2021-europaediatrics.51}

Introduction Sleep-related breathing disorders are a potentially lethal conditions characterized by multiple episodes of sleep apnea. Study of these conditions seems to be relevant for pediatrics due to the difficulties of diagnosis and the lack of actual effective treatment strategies. This article describes the 